\title{
Effect of Fuel Injector Nozzle Hole Diameter on Emissions of CAT 3401 Diesel Engine Using CONVERGETM CFD
}

\author{
Vishal Kumbhar, Anand Kumar Pandey, Anil Varghese
}

\begin{abstract}
Variation of fuel injector nozzle hole is on engine emission and performance is evaluated in present article. Simulation is carried out on caterpillar 3401 diesel engine is using CONVERGE CFD code. A $60^{\circ}$ sector model with SAGE combustion model was considered to examine the four different nozzle hole diameters $(0.230 \mathrm{~mm}, 0.240 \mathrm{~mm}, 0.250 \mathrm{~mm}, 0.259 \mathrm{~mm}$ and $0.270 \mathrm{~mm}$ ) and their effect on the engine performance, emissions and spray characteristics. The combustion results showed that nozzle hole diameter of $0.230 \mathrm{~mm}$ contributed for maximum in-cylinder pressure and temperature due to enhancement in spray cone angle, atomization, and efficient air-fuel mixture. $\mathrm{HC}, \mathrm{CO}$, and soot Emissions were found to be decreased with the decrease in nozzle hole diameter, however, due to enhanced atomization and the overall increase in cylinder gas temperature, the NOx emissions were observed to increase for nozzle holes with smaller diameters. Droplet radius for $0.250 \mathrm{~mm}$, $0.259 \mathrm{~mm}$ and $270 \mathrm{~mm}$ is found to be larger to the formation of lower jet velocities. Thus nozzle holes with smaller diameter tend to reduce the emissions with a penalty in NOx emission.
\end{abstract}

Index Terms: CONVERGE CFD, combustion, emissions, atomization, spray

\section{INTRODUCTION}

. Lots of efforts are being made into reducing the engine pollutant and greenhouse emissions to explore clean biofuels for $\mathrm{CI}$ and SI engines new[1][2][3][4]. Engine downsizing concept has led to improve the engine performance however, the problem of NOx and Soot emissions is still the major concern. Various studies have shown that the NOx and soot emissions have unfavorable effects on the environment and on human health[5]. Stringent emissions and regulations require cleaner combustion technologies.

After-treatment systems like SCR, DPF, NOx trap, Exhaust gas recirculation are used to control the emissions. However, these systems face issues of cost, durability and

Revised Manuscript Received on October 30, 2019.

* Correspondence Author

Vishal Kumbhar*, Dept. of Mechanical Engineering, Symbiosis Institute of Technology, Symbiosis International University. Pune, India

Colonel (Dr.) Anand Kumar Pandey, Dept. of Mechanical Engineering, Symbiosis Institute of Technology, Symbiosis International University Pune, India.

Anil Varghese, Dept. of Mechanical Engineering, Symbiosis Institute of Technology, Symbiosis International University. Pune, India

(c) The Authors. Published by Blue Eyes Intelligence Engineering and Sciences Publication (BEIESP). This is an open access article under the CC BY-NC-ND license (http://creativecommons.org/licenses/by-nc-nd/4.0/) increased fuel consumption. Hence research is dedicated towards on in-cylinder technologies to control the emissions. Fuel injectors are the most vital element of diesel engine and often known as 'heart of engine'. Fuel injector delivers the right amount of fuel as per the engine requirement with high pressure required for the proper fuel atomization, mixing with air which in turn provided efficient combustion and thereby controlled emissions. Various fuel injection parameters such as the number of nozzles, diameter, and spray angle contribute to combustion due to spray parameters such as spray length and droplet size. Many researchers have focused on the effect of nozzle configurations such as the number of holes, nozzle diameter, and nozzle length on engine performance and emissions.

Effect of two injector nozzles of diameter $0.16 \mathrm{~mm}$ and $0.08 \mathrm{~mm}$ with three different injection pressures investigated by Montgomery et.al [6] showed that nozzle diameter of $0.08 \mathrm{~mm}$ with an injection pressure of $100 \mathrm{Mpa}$ lowered the soot formation as a result of impinging spray flame. Thus the grouping of smaller diameter with high injection pressures provided better atomization, spray penetration and spray impingement on the cylinder walls. Subash Lahane and K. Subramanian [7] studied the variation of nozzle diameter on spray penetration using a modified nozzle configuration $(0.188 \mathrm{~mm} \times 6$ holes). They found that the modified nozzle configuration enhanced the air-fuel mixing which resulted in lesser smoke emissions (38\% opacity) as compared to baseline nozzle configuration (40\% opacity). Also, NOx emissions were observed to decrease with increasing the nozzle holes from 5 to 6 . Nozzle fuel flow and spray formation were studied numerically by Michele Battistoni and Carlo Grimaldi [8], for two nozzle shapes (conical and cylindrical). Higher flow rates were found for conical nozzle due to the result of the reduction in cavitation.

Spray atomization and turbulence strongly depends on the injection velocity at nozzle hole exit [9]. The boundary layer produced near the hole wall is observed to increase for smaller nozzle hole diameters which reduces the air-fuel ratio and mass flow rate [10]. Increase in NOx emissions was observed with, in the number of nozzle holes by Ranganatha Swamy L. et.al [11], increase in combustion rate and more heat releases during premixed combustion due to increment in holes were the possible reasons for it. M. Vijaykumar et.al [12] carried out the experimental study for three different nozzle hole diameters $(0.20 \mathrm{~mm}, 0.28 \mathrm{~mm}, 0.31 \mathrm{~mm})$, they concluded that engine performance was enhanced for all three nozzle hole diameter injectors. However, NOx emissions were observed to be increased for smaller nozzle hole diameter.

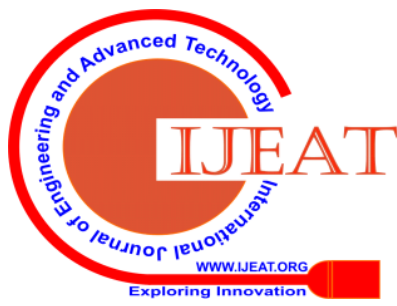


Sauter mean diameter (SMD) and arithmetic mean diameter are found for smaller nozzle hole diameter, due to the enhancement in degree of dispersion of spray droplets [13] Spray patterns for three nozzle hole diameters $(0.22 \mathrm{~mm}$, $0.32 \mathrm{~mm}$ and 0.42 ) studied by Lee and Kim [14]showed that the Sauter mean diameter decreased as diameter of hole was reduced. Larger nozzle hole diameters were observed to give higher fuelling rate due to fuel rich core region regardless of larger lift-off length[15].

Most authors have investigated the influence of injection pressure and variation of nozzle holes on performance and emissions. In present work, the effort is made on evaluating the variation of injector nozzle hole diameter on engine emissions and spray patterns using CONVERGE CFD code.

\section{NUMERICAL ANALYSIS}

The numerical model consists of the Caterpillar 3401 heavy-duty engine with injector nozzle with 6 uniform holes. Actual photograph of nozzle holes is shown in figure 2. To reduce the overall computational times the overall computational model is reduced to a $60^{\circ}$ sector model. $(360 / 6=6$, i.e. each sector is considered to have one nozzle hole). Specifications of CAT 3401 engine are given in table 1. Different views of $60^{\circ}$ sector model are shown in figure 1 . CONVERGE studio is used for numerical simulation and the results are post-processed using Paraview. Converge provides automatic mesh refinement as per the mesh movement and fluctuations using the Adaptive mesh refinement (AMR), which eliminates the need to mesh the whole model finely. The boundary conditions used for the present study are given in table 2 .
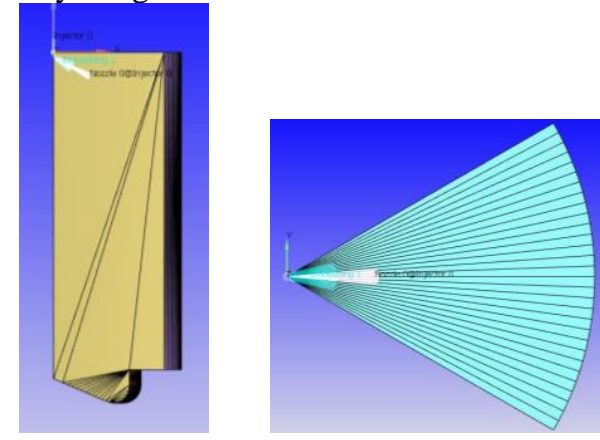

Fig. 1: Engine Sector Model

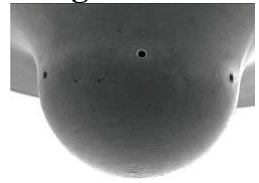

Fig.2 Photograph of the nozzle hole Table 1 Engine Specifications

\begin{tabular}{|l|l|}
\hline Bore $\times$ Stroke (mm) & $137.6 \times 165.1$ \\
\hline Connecting rod length (mm) & 261.62 \\
\hline Displacement volume (L) & 2.44 \\
\hline Compression ratio & 15.1 \\
\hline $\begin{array}{l}\text { Number of Nozzle (orifice } \\
\times \text { diameter) (mm) }\end{array}$ & $6 \times 0.259$ \\
\hline Number of cylinders & 1 \\
\hline Engine rpm & 1600 \\
\hline Injection pressure (Mpa) & 90 \\
\hline Intake valve closure & $-147^{\circ}$ aTDC \\
\hline Injection duration & $\begin{array}{l}21.5 \text { crank angle } \\
\text { degrees }\end{array}$ \\
\hline Start of Injection & $-11^{\circ}$ \\
\hline Fuel injected (g/cycle) & 0.1622 \\
\hline
\end{tabular}

Table 2 Boundary Conditions
\begin{tabular}{|l|l|l|l|}
\hline Boundary & Type & $\begin{array}{l}\text { Boundary } \\
\text { Condition }\end{array}$ & Value \\
\hline Piston & Wall & Temp. & $553 \mathrm{~K}$ \\
\hline Front face & Periodic & - & $\begin{array}{l}60^{\circ} \\
\text { periodic } \\
\text { shape }\end{array}$ \\
\hline Back face & Periodic & - & $\begin{array}{l}\text { Matched } \\
\text { to front } \\
\text { face }\end{array}$ \\
\hline $\begin{array}{l}\text { Cylinder } \\
\text { Wall }\end{array}$ & Wall & Temp. & $433 \mathrm{~K}$ \\
\hline $\begin{array}{l}\text { Cylinder } \\
\text { Head }\end{array}$ & Wall & Temperature & $523 \mathrm{~K}$ \\
\hline
\end{tabular}

\section{A. Combustion and spray modeling}

SAGE combustion model available in converge studio [16] is used for present simulation. SAGE uses the principles of chemical kinetics to calculate the reaction rates using local conditions. The SAGE model runs in parallel with flow solver which speed up the overall simulation. With suitable reactions mechanism, SAGE can be used to analyze different combustion phenomenon in both diesel and gasoline engines. Converge consists, various models, to simulate the NOx and soot produced during combustion. Along with these $\mathrm{CO}$, $\mathrm{CO} 2$ and UHC are interpolated in converge with appropriate reaction mechanism. The different emission models considered in the simulation are given in table 3 .

Table 3 Emissions models

\begin{tabular}{|l|l|}
\hline Emission & \multicolumn{1}{|c|}{ Model } \\
\hline NOx & Thermal NOx model (Extended Zeldovich) \\
\hline Soot & Hiroyasu soot model \\
\hline
\end{tabular}

Spray simulation is calculated by CONVERGE using drop parcels in the computational domain. Parcels consist of a group of identical drops with uniform diameter, same velocity, and temperature which are used to represent the entire spray pattern. The different models associated with spray simulation are presented in table 4 .

Table 4 Combustion and Spray Models

\begin{tabular}{|c|c|}
\hline Breakup & KH-RT \\
\hline Collision & NTC \\
\hline Drop drag & Dynamic drag \\
\hline Evaporation & Multi-component vaporization \\
\hline
\end{tabular}

In present work engine in-cylinder performance, emissions and spray characteristics (spray penetration length, droplet size and Sauter mean diameter) are analyzed for 4 different nozzle hole diameters $(0.230 \mathrm{~mm}, 0.240 \mathrm{~mm}, 0.250 \mathrm{~mm}$, $0.259 \mathrm{~mm}$ (Baseline diameter) and $0.270 \mathrm{~mm}$ ).

\section{VALIDATION OF NUMERICAL RESULTS}

The numerical results obtained from CONVERGE CFD are verified using the experimental data from Curtis et.al [15] on CAT 3401 engine. All the engine and simulation parameters were kept similar to those of the experiment. The simulation is carried out for baseline nozzle diameter of $0.259 \mathrm{~mm}$. Figure 3 (a \& b) represents in-cylinder pressure and temperature validation of numerical and experimental data.

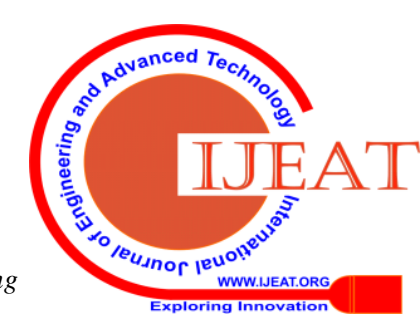




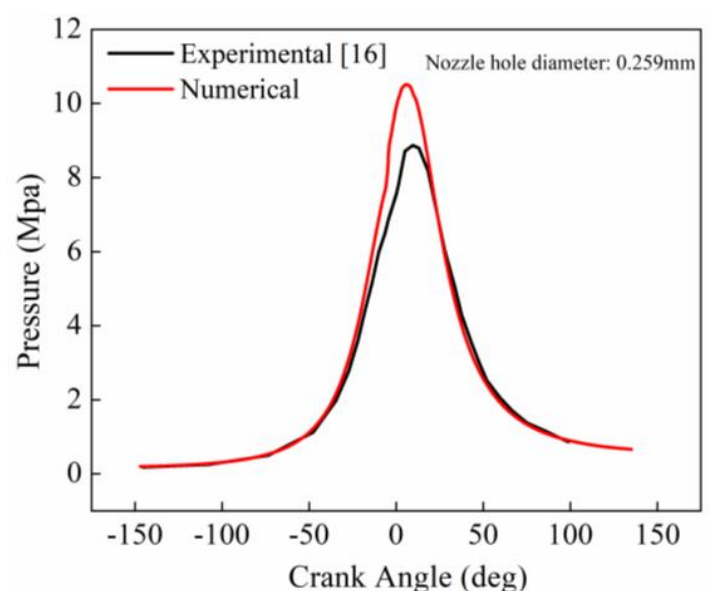

(a)

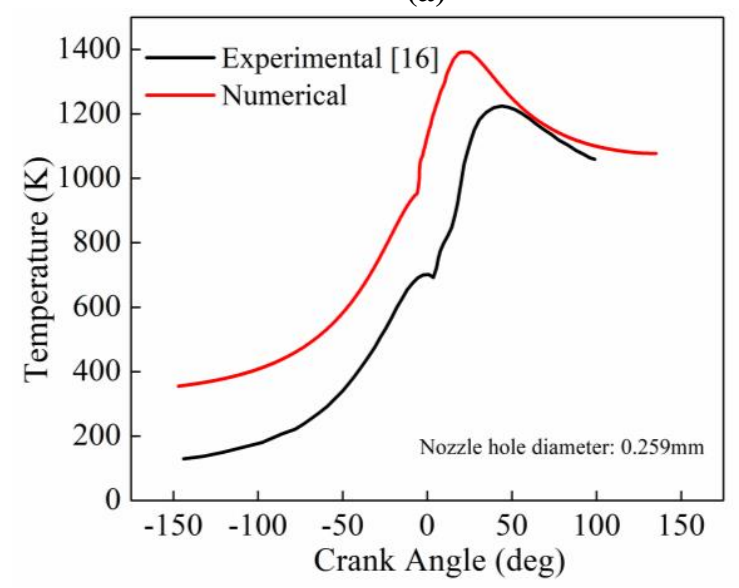

(b)

Fig. 3 Validation of cylinder pressure and temperature of numerical and experimental data with baseline hole diameter of $0.259 \mathrm{~mm}$

\section{RESULTS AND DISCUSSION}

\section{A. Cylinder pressure and temperature}

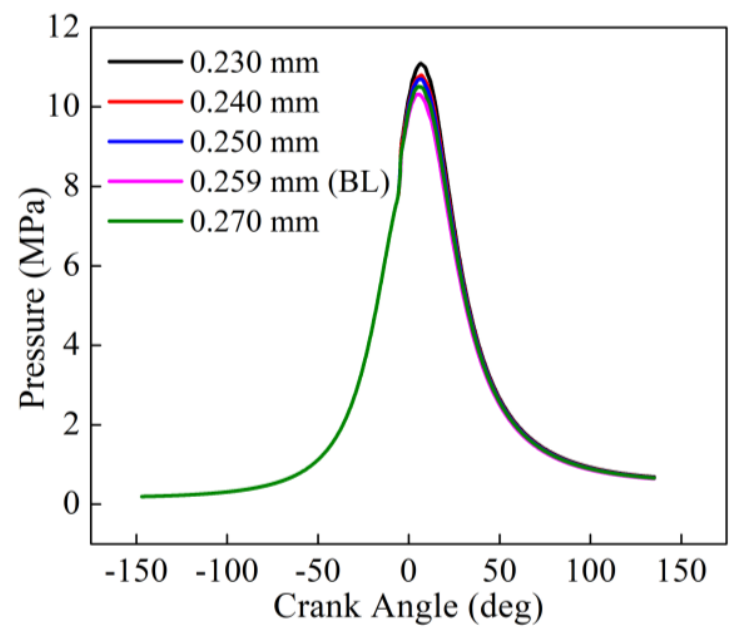

Fig.3 Cylinder pressure for different hole diameters

Figure 3 shows the effect of hole diameter on cylinder pressure. It is seen that the smaller diameter holes produced higher cylinder pressure. The nozzle hole with smaller diameter provides the proper mixing of fuel and air due to the smaller fuel rich core of the fuel spray, which also results in an increase in overall in-cylinder temperature for smaller nozzle hole diameter.

Hence it can be observed that nozzle hole with $0.230 \mathrm{~mm}$ diameter provided higher in-cylinder pressure and temperature amongst the others.

Ignition delay tends to increase pressure and temperature. For smaller nozzle diameter holes the increase in gas temperature in the combustion chamber increases, which lowers the delay period. Enhancement in spray cone angle, atomization and efficient air-fuel mixture in smaller nozzle hole diameters contributes to efficient combustion which results in increased in-cylinder temperature as seen in figure 4.

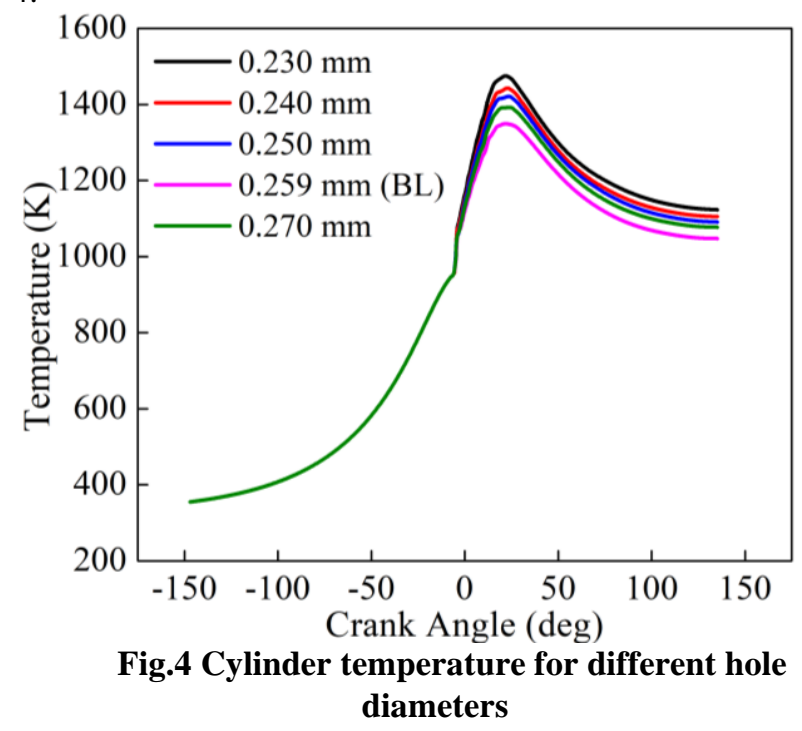

\section{B. Engine emissions}

Figure 5 and 6 show the variation of $\mathrm{CO}$ and $\mathrm{HC}$ emissions for four different nozzle diameters. Hydrocarbons emissions are produced due to incomplete combustion. The HC and CO emissions are observed to decrease as the diameter of nozzle decreases, this is because of reduction in the wall-impingement for smaller diameter nozzles compared to larger diameter nozzle.

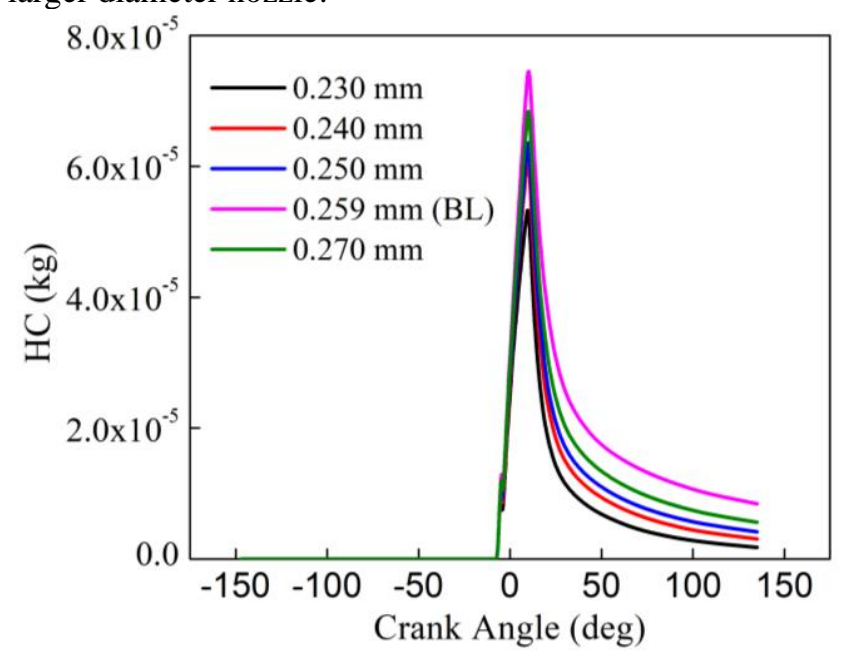

Fig.5 Effect on HC emissions

Also smaller diameter nozzle hole enhances the good atomization and uniform distribution of fuel. Larger nozzle hole diameter led to the quenching reaction on wall surfaces as a result of lesser temperature in the combustion chamber due to reduced atomization and partial fuel evaporation [17].

The particle size is observed to increase with an increase in nozzle diameter which resists the fuel mixture to burn efficiently thereby increasing the $\mathrm{HC}$ and $\mathrm{CO}$ emissions in case of larger nozzle diameter.

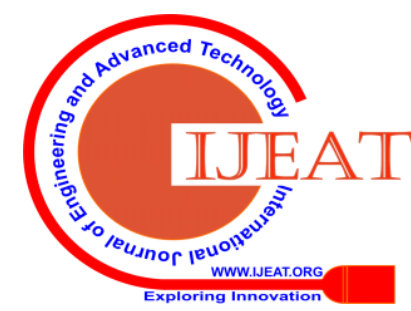




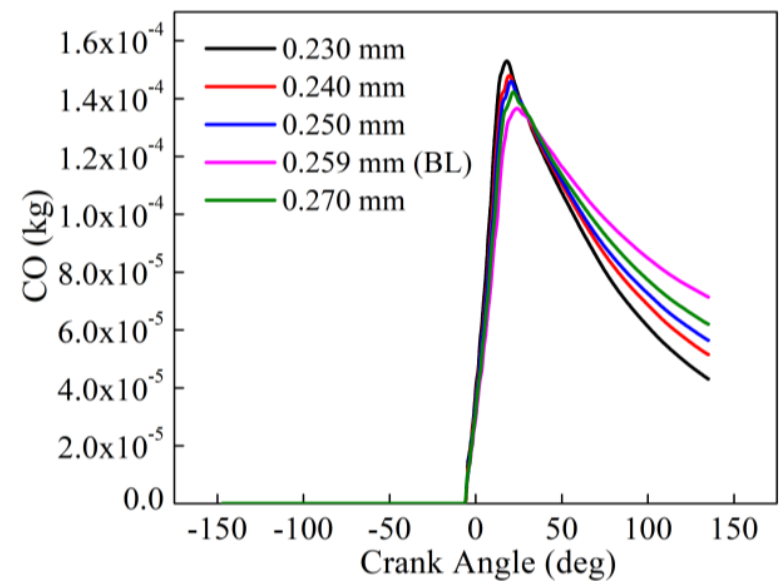

Fig.6 Effect on CO Emissions

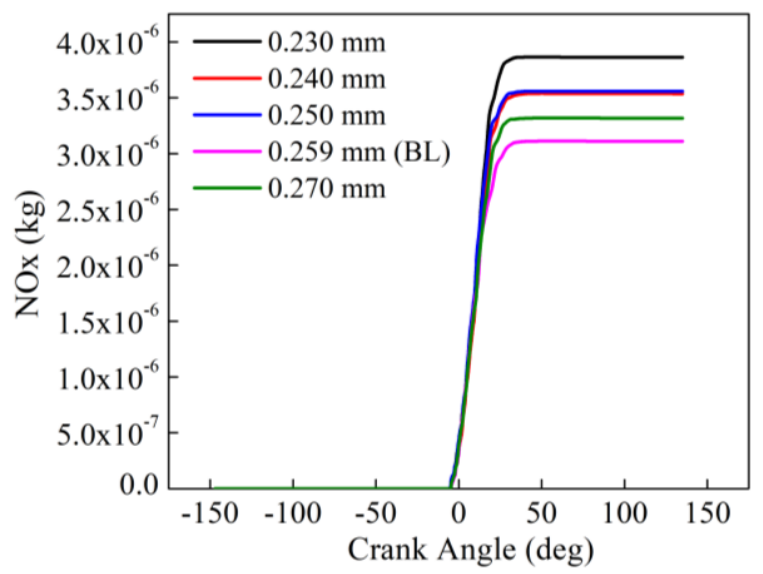

Fig.7 Effect on NOx Emissions

Figure 7 shows the variation of NOx emissions for different nozzle diameters. Smaller nozzle diameter provides enhanced atomization which increases the overall cylinder gas temperature, which thereby increases the NOx emissions. While poor atomization and uneven particle distribution reduces the overall in-cylinder temperature for larger nozzle diameter and decreases the NOx emissions.

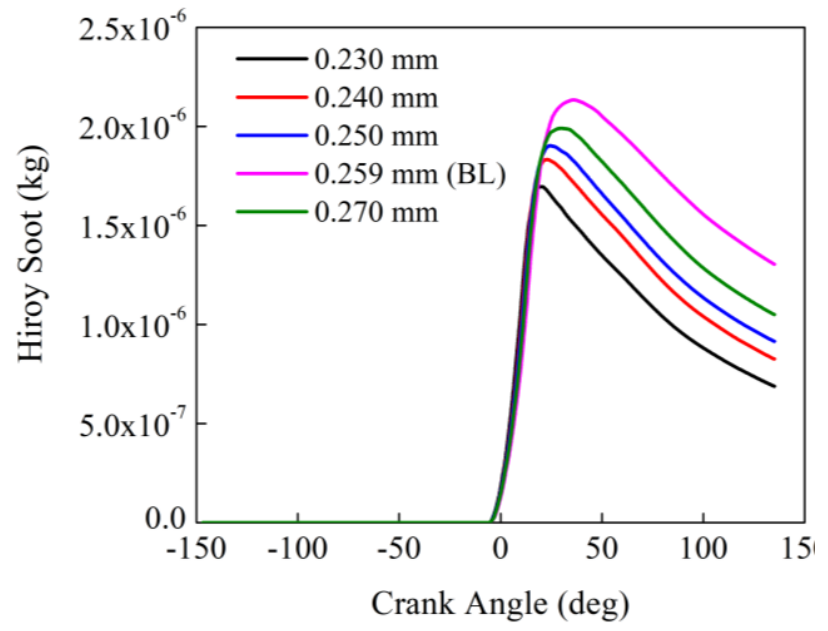

Fig.8 Effect on Soot Emissions

For smaller nozzle hole diameters the soot formation decreases due to the decrease as the quantity of air-fuel mixing upstream of the lift-off length decrease [18]. Thus smaller diameter nozzle holes increase the air-fuel mixing which leads to decrease in soot formation as shown in figure 8.

\section{SPRAY CHARACTERISTICS}

\section{A. Spray penetration length}

Figure 9 represents the variation of spray penetration for various hole diameters. As the diameter increases the spray penetration is observed to increase at the same crank angle. It is reported that increasing the nozzle diameter cavitation tends to increase which increases the spray penetration [19]. More efficient combustion can be obtained with a combination of high swirl ratio and hot walls along with longer penetrations of spray. However high spray penetration produces the undesirable fuel contact on the wall of the cylinder which reduces the fuel/air mixing rates which results in an increase in emissions.

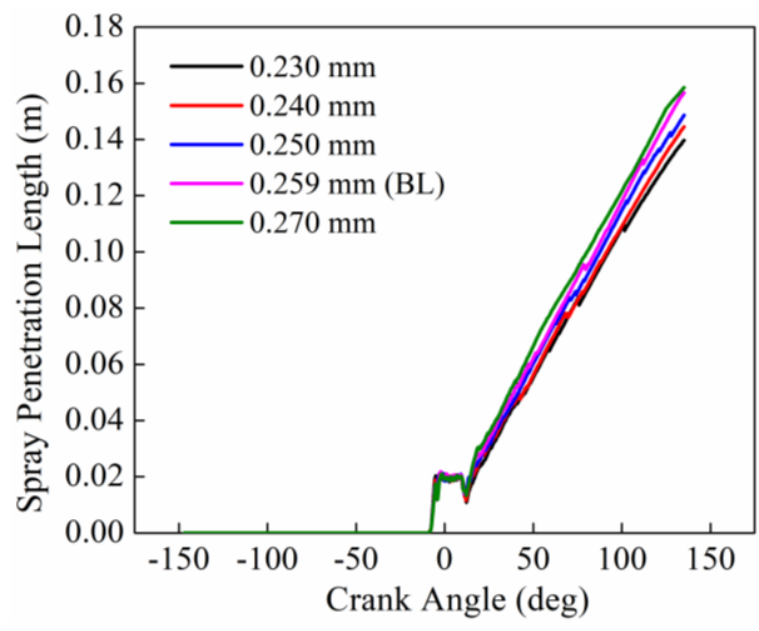

Fig.9 Variation of spray penetration length

B. Fuel spray diameter and velocity

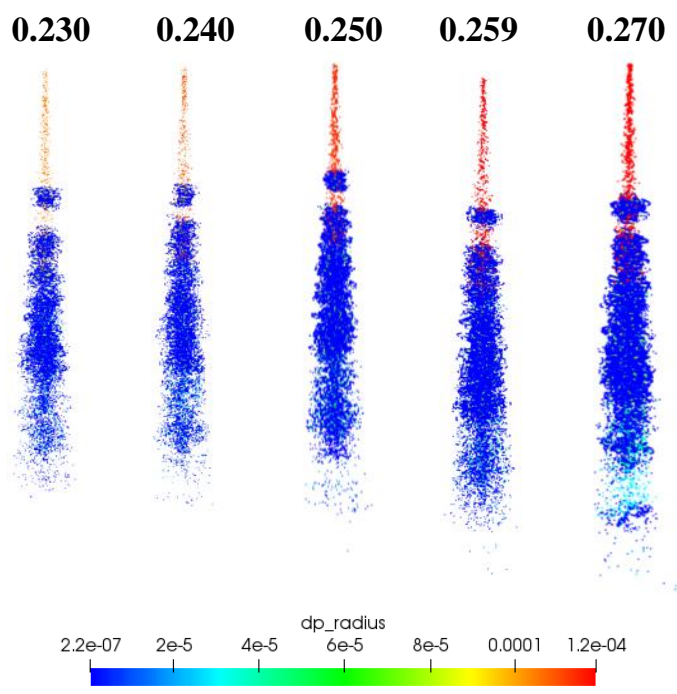

Fig. 10 Fuel spray particle diameter distribution.

Figure 10 shows the spray particle radius distribution for different nozzle hole diameters. Larger diameters of $0.259 \mathrm{~mm}$ and $0.270 \mathrm{~mm}$ the radius of the droplet is larger than other nozzle hole diameters, this is due to the formation of lower jet velocities which causes droplets to become larger

than nozzle diameter. Nozzles with smaller diameter create the high spray velocities which result in an early breakup, thereby creating droplets smaller than the injector nozzle diameter. 
0.230

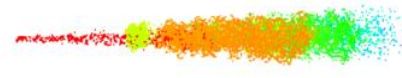

0.240

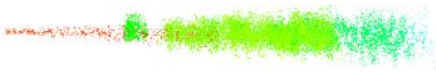

0.250

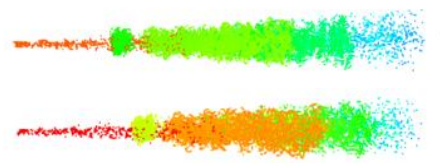

0.259

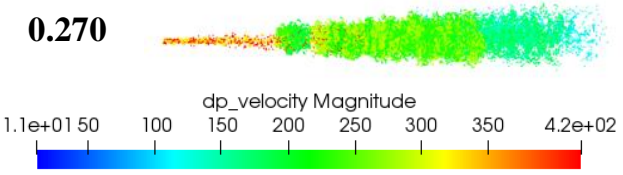

Fig. 11 Fuel spray velocity distribution

Additionally, for larger diameter, the injection velocity is reduced as observed in figure 11, which enhances the spray breakup and mixing rates. However, the lower jet velocities cause the droplets to become much larger than the nozzle diameter due to fluctuations in surface waves as a result of surface tension effects, which reduces atomization and evaporation speeds [20].

\section{Sauter mean diameter (SMD)}

Figure 12 shows the variation of spray Sauter mean diameter (SMD) for different nozzle hole diameters. SMD is initially large after injection however, with the increase in fuel injection rate SMD tends to decrease. At the start of the spray nozzle diameter, injection pressure affects the fuel evaporation characteristics [21]. Once the fuel starts forming small drop SMD decreases as a result of droplet break-up, atomization, and evaporation. Hence as nozzle hole diameter increases, SMD is observed to increase due to delay in breakup and atomization.

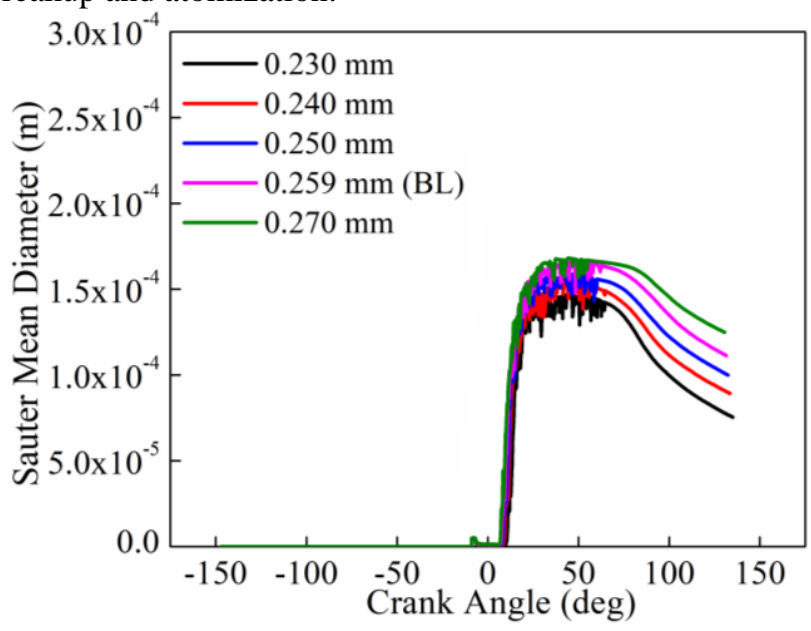

Fig. 12 Effect on Sauter Mean diameter

\section{CONCLUSION}

Engine performance and emissions is evaluated by varying the nozzle hole diameter and simulated using CONVERGE CFD, the following conclusions are drawn from the study,

1. Cylinder pressure and temperature was found to be maximum for nozzle hole with $0.230 \mathrm{~mm}$ diameter, due to efficient mixing of fuel and air due to the smaller fuel rich core of the fuel spray.

2. $\mathrm{HC}$ and $\mathrm{CO}$ emissions decreased with decreased in hole diameter, due to the reduction in the wall-impingement for smaller diameter nozzles compared to larger diameter nozzle.

3. Smaller nozzle diameter provides enhanced atomization which increases the overall cylinder gas temperature, which increases the NOx emissions.

4. Smaller diameter nozzle hole increases the air-fuel mixing which leads to decrease in soot formation.

5. As the diameter increases the spray penetration is observed to increase at the same crank angle. Increasing the nozzle diameter, cavitation tends to increase which increases the spray penetration.

6. Sauter mean diameter is observed to increase with enlargement of nozzle hole due to delay in breakup and atomization

\section{ACKNOWLEDGEMENT}

Authors are thankful to SkillLync, Chennai for providing the CONVERGE ${ }^{\mathrm{TM}} \mathrm{CFD}$ software.

\section{REFERENCES}

1. A. K. Pandey, M. Nandgaonkar, S. Suresh, and A. Varghese, "The Effect of Cerium Oxide Nano Particles Fuel Additive on Performance, Combustion, NOx Reduction and Nano Particle Emission of Karanja and Jatropha Biodiesel in a Military $585 \mathrm{~kW}$ CIDI Engine." SAE International , 2019.

2. A. K. Agarwal, "Biofuels (alcohols and biodiesel) applications as fuels for internal combustion engines," Progress in Energy and Combustion Science, vol. 33, no. 3. pp. 233-271, 2007.

3. A. K. Pandey and M. R. Nandgaonkar, "Experimental Investigation of the Effect of Esterified Karanja Oil Biodiesel on Lubricating Oil and Wear of a 780 hp Military CIDI Engine," SAE Int. J. Fuels Lubr., vol. 3, no. 2, pp. 273-279, 2010.

4. J. Xue, T. E. Grift, and A. C. Hansen, "Effect of biodiesel on engine performances and emissions," Renew. Sustain. Energy Rev., 2011.

5. J. Kagawa, "Health effects of diesel exhaust emissions * a mixture of air pollutants of worldwide concern," vol. 182, pp. 349-353, 2002.

6. D. T. Montgomery, M. Chan, C. T. Chang, P. V Farrell, and R. D. Reitz, "Effect of Injector Nozzle Hole Size and Number on Spray Characteristics and the Performance of a Heavy Duty D.I. Diesel Engine." SAE International , 1996.

7. S. Lahane and K. A. Subramanian, "Impact of nozzle holes con fi guration on fuel spray, wall impingement and NO x emission of a diesel engine for biodiesel e diesel blend ( B20 )," Appl. Therm. Eng., vol. 64, no. 1-2, pp. 307-314, 2014.

8. M. Battistoni and C. N. Grimaldi, "Numerical analysis of injector flow and spray characteristics from diesel injectors using fossil and biodiesel fuels," Appl. Energy, vol. 97, pp. 656-666, 2012.

9. A. Kumar, S. Som, P. Chandra, H. Goyal, and D. Longman, "In-nozzle flow and spray characteristics for mineral diesel , Karanja , and Jatropha biodiesels," Appl. Energy, vol. 156, pp. 138-148, 2015.

10. M. Jangi, X. Bai, H. Walther, and J. Fournier, "ScienceDirect ScienceDirect ScienceDirect Effects of Nozzle Diameter on Diesel Spray Flames: A numerical The 15th International Symposium on District Heating and Cooling study using an Eulerian Stochastic Field Method b using the heat Assessing of Kar Mun the Pang feasibility temperature function for a long-term district heat demand forecast," Energy Procedia, vol. 142, pp. 1028-1033, 2017.

11. R. S. L, T. K. Chandrashekar, N. R. Banapurmath, and P. Nashipudi, "Effect of Injection Timing, Combustion Chamber Shapes and Nozzle Geometry on the Diesel Engine Performance," vol. 2, pp. 74-95, 2014.

12. T. Science, "EFFECT OF THE INJECTION PRESSURE ON THE INTERNAL FLOW CHARACTERISTICS FOR DIETHYL AND DIMETHYL ETHER," vol. 15, no. 4, pp. 1123-1130, 2011.

13. K. Nishida, J. Zhu, X. Leng, and Z. He, "Effects of micro-hole nozzle and ultra-high injection pressure on air entrainment , liquid penetration , flame lift-off and soot formation of diesel spray flame," vol. 18, pp. 51-65, 2017.

14. C. Sik and S. Wook, "An experimental and numerical study on fuel atomization characteristics of high-pressure diesel injection sprays q," vol. 81, pp. 2417-2423, 2002. 
15. E. W. Curtis, A. Uludogan, and R. D. Reitz, "A New High Pressure Droplet Vaporization Model for Diesel Engine Modeling." SAE International , 1995.

16. "scholar." S. Jabbar, M. Algayyim, and A. P. Wandel, "The Impact of Injector Hole Diameter on Spray Behaviour for Butanol-Diesel Blends," vol. v, no. Cvv, 2018.

17. H. Chaves, M. Knapp, A. Kubitzek, F. Obermeier, and T. Schneider, "Experimental Study of Cavitation in the Nozzle Hole of Diesel Injectors Using Transparent Nozzles.” SAE International , 1995.

18. S. Yu et al., "Experimental study on the spray and mixing characteristics for equilateral triangular and circular nozzles with diesel and biodiesel under high injection pressures," vol. 239, no. October 2018, pp. 97-107, 2019.

19. Y. Gao et al., "Experimental study of the spray characteristics of biodiesel based on inedible oil," Biotechnol. Adv., vol. 27, no. 5, pp. 616-624, 2009.

20. M. T. Shervani-tabar, M. Sheykhvazayefi, and M. Ghorbani, "Numerical study on the effect of the injection pressure on spray penetration length," Appl. Math. Model., 2013.

\section{AUTHORS PROFILE}

Vishal Kumbhar, Junior Research Fellow, Symbiosis Institute of Technology, Pune, India. Has 2 publications in international journals and 2 publications in national journals. His research area is use of biofuels for IC Engines.

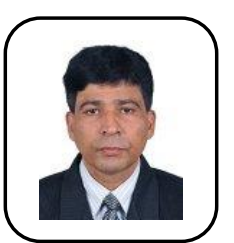

Colonel (Dr.) Anand Kumar Pandey, Professor, Symbiosis Institute of Technology Pune. Has 13 publications in SAE journals. His research area is biofuels for military vehicles, electric vehicles, GDI engines, HCCI engines.

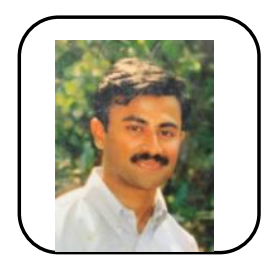

Anil Varghese, Research Scholar, Symbiosis Institute of Technology Pune. Has 2 publications in $\mathrm{SAE}$ journals. His research area is GDI engines, HCCI engines. 